\title{
PUBLISHING PERFORMANCE OF SPANISH ACADEMICS: 1970-2004
}

\author{
David Rodríguez \\ Institut d'Anàlisi Econòmica (CSIC)
}

April 6, 2005

\begin{abstract}
The aim of this note is to complement some of the results appearing in Dolado et al. (2003) article "Publishing Performance in Economics: Spanish Rankings". We want to focus on three issues: the robustness of the results regardless of the time span considered, the evaluation of the contribution of a researcher to the advance of knowledge, and to what extent the choice of a particular database can affect the results. Differences are significant when we expand the time period considered. There are also small but significant differences if we combine datasets to derive the rankings.
\end{abstract}

Keywords: rankings, economics, bibliometric indicators

JEL Classification: A10, A14

Unlike its American counterpart, the European literature on measuring the economists' performance is relatively recent and traces back from the beginning of the nineties. Probably one of the main reasons of this recent concern on research performance has been the common trend in European countries towards increasing academic competition, which is needed of some measures of academic evaluation.

This literature has focused on analyzing the productivity of scientists and/or departments based on a series of bibliometric indicators (such as the publications or their impact on the academic community) in a given period of time, generally no longer than ten years. Several indicators have been used as proxies of productivity but up to now there is no universally accepted measure ${ }^{1}$.

Among the flow of recent studies, the contrbution of Dolado et. al (2003) attracted the attention of the Spanish academic profession since (a) it focuses specifically on the

\footnotetext{
* Correspondence address: Institut d'Anàlisi Econòmica (CSIC), Campus UAB, 08193 Bellaterra, Barcelona, Spain; david.rodriguez@uab.es. I would like to thank Roberto Burguet and Ramon Caminal for his useful comments, and Ana Belmonte and David Martínez for their help.

${ }^{1}$ See Coupé (2003) for a detailed explanation of families of indicators used in the literature.
} 
Spanish case; and (b) introduces a new way of valuating publications that avoids several of the usual shortcomings of the traditional methods. This new way of assessing performance (called UC3 index) takes into account and corrects the traditional underestimation of contributions to Spanish academics journals; and publications in areas in the boundary of economics but with significant impact, such as econometrics or economic history.

This new measure however is still subject to the usual criticisms of these studies: it considers only a relatively short time span, unable of capturing the overall productivity of a researcher. If one of the final purposes of the rankings is to consider a relative position of a researcher in order to evaluate her overall contribution to the advance of knowledge, or even to allocate funds or compete for an academic position, considering only the most recent productivity track can be misleading and probably unfair ${ }^{2}$.

The aim of this note is precisely try to give some hints to this open question and analyze whether the time span considered matters. In order to do this we shall consider different time horizons and recompute the bibliometric measures used in Dolado et al. to check for significant changes. Section 2 will explain the methodology used to do this exercise and section 3 will present the main results. In Section 4 we shall extend the results to 2004, giving us enough room to see differences with respect the original end of period.

\section{Methodology}

In order to replicate the results of the original study, we have concentrated on the set of the top-10 Spanish academic economists, i.e. those working in a Spanish academic institution or being a Spanish citizen. Since there are different ranking measures, we shall consider those who at least appear once in Tables 5 to 8 of the original study by Dolado. This gives a total number of 22 scientists. Some of them (Boldrin, Canova, Motta and Saint-Paul) are not working right now in a Spanish institution, but actually

\footnotetext{
${ }^{2}$ Another common trend in European countries is to allocate funds based on bibliometric results. For instance, government funds for research in university hospitals in Finland and partly based on publication points given by the impact factor of the journals in which researchers publish. (Adam 2002).
} 
only Gilles Saint-Paul does not keep any formal relationship with a Spanish institution ${ }^{3}$. From this set we have proceeded to download, using Econlit and the Social Sciences Citation Index (SSCI) the list of their publications and citations received. To avoid possible inconsistencies, we have double-checked the information with the corresponding $\mathrm{CV}$ obtained either by their own web pages or their department ${ }^{4}$.

To calculate the rankings we have used three different measures: the first one is the UC3 index, based on Dolado et al. (2003); the second one is the newest version of the KMS index, developed by Kalaitzidakis et al. (2003), and including 30 top-ranked journals; finally, the last one is the index developed by Bauwens (1998), which covers a broad sample of economics journals. Details of these criteria can be found in Box 1 . Although there are other alternative measures, we have decided to concentrate on these three, since the remaining ones used in the original work were modified versions of the former two.

BOX 1: DEFINITION OF THE CRITERIA USED FOR ELABORATE THE RANKINGS (BASED ON DOLADO ET. AL)

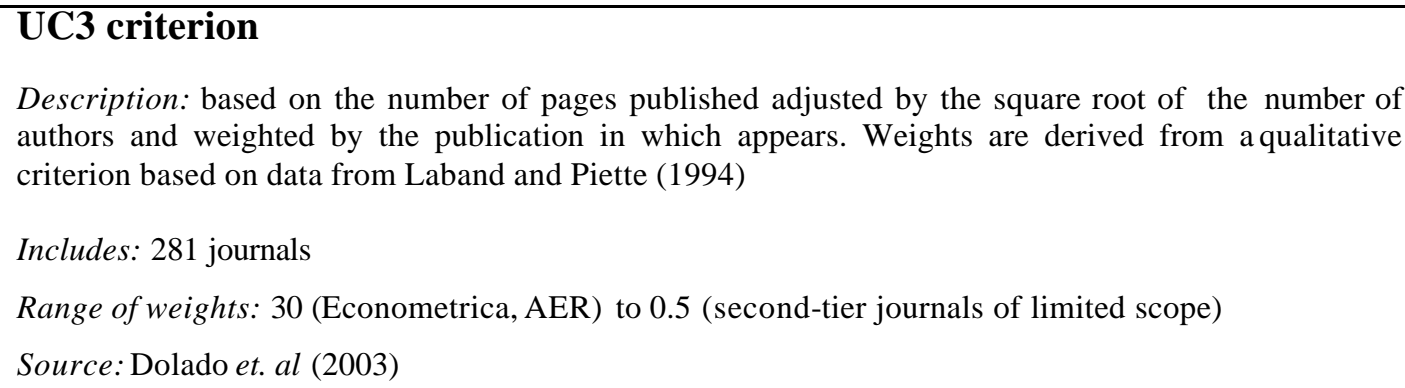
authors and weighted by the publication in which appears. Weights are derived from a qualitative criterion based on data from Laband and Piette (1994)

Includes: 281 journals

Range of weights: 30 (Econometrica, AER) to 0.5 (second-tier journals of limited scope)

Source: Dolado et. al (2003)

\section{BAU criterion}

Description: based on the number of articles published divided by the number of authors and weighted by the publication in which appears. Weights are based on an ordinal scale derived by multypliying the total number of citations a publication receives and its corresponding impact factor.

Includes: 265 journals

Range of weights: 5 (Econometrica, AER) to 1 (second-tier journals of limited scope)

Source: Bauwens (1998)

\footnotetext{
3 The remaining three authors keep permanent positions in Spanish institutions, although they are on leave.

${ }^{4}$ In only one case we were not able to obtain the original C.V. There were significant differences in one case, since several of the journals reported on the CV did appear in neither SSCI nor Econlit. After verifying them through the journal summaries we decided to include them.
} 


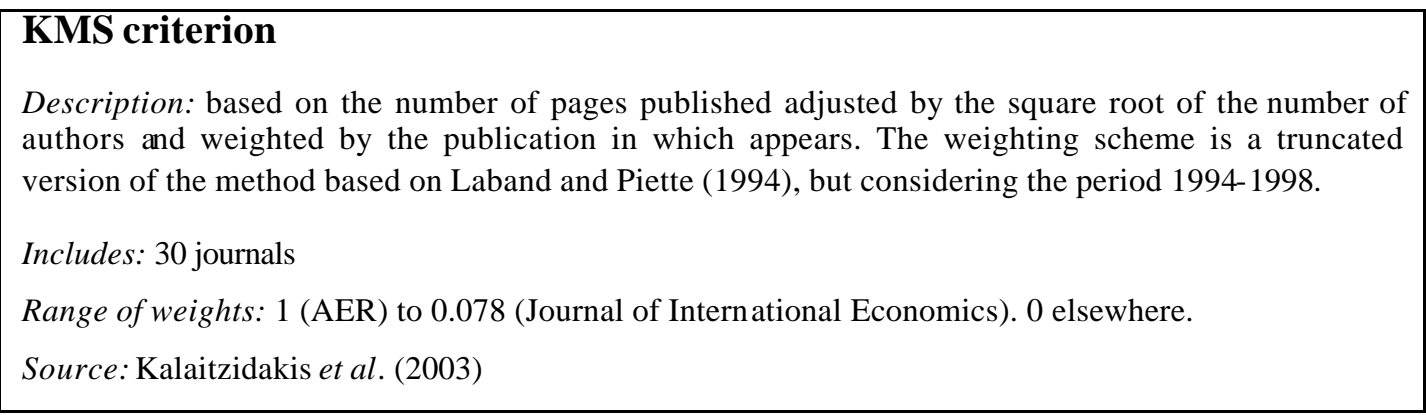

We have considered several time spans to check the robustness of the results: the first one is the period considered in the study (1990-1999); the second is the period 19851999; the third the period 1980-1999 and the fourth is the total length as researcher. We have defined the researcher-life as the range between 1999 and the year of their first international article registered in Econlit. As one can see from Table 1, the average researcher-life is relatively small (13 years). Less than one quarter of the sample have publications prior to 1985 and only three of them before 1980. The total range, however is high enough (21 years), suggesting we have at least three generations of scientists: those whose publications first appeared during the seventies (Barberà, Esteban ${ }^{5}$, MasColell and Silvestre), those whose publications first appeared during the first years of the eighties (Repullo and Vives), and a broad generation of young economists who first published at the end of the eighties and the beginning of the nineties.

Table 1: Year of first recorded international publication

\begin{tabular}{llll}
\hline Arellano & 1987 & Motta & 1992 \\
Barberà & 1977 & Repullo & 1982 \\
Bentolila & 1990 & Rios-Rull & 1992 \\
Boldrin & 1986 & Saint-Paul & 1991 \\
Canova & 1991 & Sala-i-Martin & 1991 \\
Dolado & 1986 & Santos & 1989 \\
Esteban & 1972 & Sentana & 1991 \\
Galí & 1990 & Serrano & 1993 \\
Marcet & 1988 & Silvestre & 1977 \\
Marimon & 1987 & Vega-Redondo & 1985 \\
Mas-Colell & 1972 & Vives & 1984 \\
\hline
\end{tabular}


One word of caution is needed before proceeding with the calculations: the indexes considered rely on journal weights sensible to the time-span considered, since most of them are based on data from the nineties. This fact is especially strong in Kalaitzidakis et al. and Bauwens, but somewhat mitigated in Dolado et al.. We think however that this shortcoming is not severe here since we are looking at the top end of the distribution, most of whom publishing mainly in the blue-ribbon journals, where the problem of time inconsistency is less severe. According to Laband and Piette (1994), time inconsistency is more pronounced under two situations: (a) second-tier generalist journals, which have been decreasing their impact on the community and (b) journals specialized in a particular area, whose share have gradually increased over time. Indeed this problem would only potentially affect a very small fraction of the sample, those whose bulk of academic publications was produced before 1990 .

Finally we have followed the same methodology for building rankings but considering citations instead of publications.

\section{Results}

Tables 2 to 4 show the relative positions of the ten most productive economists according to the different criteria (indexed to 100-point scale). At a first glance we can see that results derived from the UC3 and KMS criteria tend to be comparable, whereas the BAU criterion seems to produce different outcomes than the previous two. This is not a surprising result, and has been found in previous studies. Concentrating in the former two, we can see that increasing the time span tends to benefit certain senior researchers as one would expect. The most striking case is Andreu Mas-Colell, who does not appear in the list if we consider only the nineties, but tops the list if we consider longer time spans. Out of this case, we can see some stability in the tables, especially if we consider the top positions. Jordi Galí is benefited if we consider shorter

\footnotetext{
${ }^{5}$ The first article of Joan Esteban appearing in both Econlit and SSCI dates from 1985. However, he had published two articles in Regional and Urban Economics in 1972, which do not appear in any of the reference databases.
} 
time spans, while Xavier Vives is the most benefited if we consider intermediate periods (for instance, considering the 20-year span covering the eighties and the nineties).

Table 2: Classification according to the UC3 Criterion

\begin{tabular}{lllllllll}
\hline & Up to 1999 & \multicolumn{3}{c}{ 1980-1999 } & \multicolumn{3}{c}{ 1985-1999 } & \multicolumn{3}{c}{ 1990-1999 } \\
\hline 1 & Mas-Colell & 100 & Vives & 100 & Vives & 100 & Galí & 100 \\
2 & Vives & 79.4 & Galí & 80.3 & Galí & 85.6 & Canova & 80.3 \\
3 & Galí & 63.7 & Mas-Colell & 75.7 & Canova & 68.7 & Vives & 74.5 \\
4 & Canova & 51.2 & Canova & 64.5 & Mas-Colell & 61.8 & Santos & 65.5 \\
5 & Barberà & 43.8 & Santos & 55.0 & Santos & 58.6 & Saint-Paul & 64.6 \\
6 & Santos & 43.6 & Saint-Paul & 51.9 & Saint-Paul & 55.3 & Vega-Redondo & 55.9 \\
7 & Silvestre & 42.4 & Vega-Redondo & 50.1 & Vega-Redondo & 53.4 & Sala-i-Martin & 49.4 \\
8 & Saint-Paul & 41.2 & Silvestre & 48.0 & Dolado & 45 & Rios-Rull & 47.4 \\
9 & Vega-Redondo & 39.8 & Dolado & 44.8 & Sala-i-Martin & 42.3 & Dolado & 44,1 \\
10 & Dolado & 32 & Barberà & 42.7 & Marimon & 41.5 & Boldrin & 42.5 \\
\hline
\end{tabular}

Table 3: Classification according to the BAU criterion

\begin{tabular}{|c|c|c|c|c|c|c|c|c|}
\hline \multicolumn{3}{|c|}{ Up to 1999} & \multirow{2}{*}{$\begin{array}{l}\text { 1980-1999 } \\
\text { Vives }\end{array}$} & \multicolumn{3}{|c|}{ 1985-1999 } & \multicolumn{2}{|l|}{$1990-1999$} \\
\hline 1 & Mas-Colell & 100 & & 100 & Vives & 100 & Saint-Paul & 100 \\
\hline 2 & Vives & 75.6 & Silvestre & 79.1 & Saint-Paul & 79.5 & Canova & 95.5 \\
\hline 3 & Silvestre & 66.6 & Saint-Paul & 74.7 & Canova & 75.9 & Galí & 86.1 \\
\hline 4 & Saint-Pau 1 & 56.5 & Canova & 71.4 & Galí & 68.4 & Vives & 78.7 \\
\hline 5 & Canova & 53.9 & Mas-Colell & 70.9 & Silvestre & 62.7 & Silvestre & 61.4 \\
\hline 6 & Galí & 48.6 & Galí & 64.3 & Dolado & 62.3 & Sala-i-Martin & 57.6 \\
\hline 7 & Barberà & 46.1 & Dolado & 62.6 & Mas-Colell & 50.3 & Dolado & 57,1 \\
\hline 8 & Dolado & 43.9 & Repullo & 48.2 & Vega-Redondo & 49.2 & Santos & 50.9 \\
\hline 9 & Repullo & 36.5 & Vega-Redondo & 46.2 & Repullo & 47.1 & Serrano & 45.1 \\
\hline 10 & Vega-Redondo & 34.9 & Sala-i-Martin & 43.0 & Sala-i-Martin & 45.8 & Vega-Redondo & 44.4 \\
\hline
\end{tabular}

Table 4: Classification according to the KMS criterion

\begin{tabular}{llrlrlrlr}
\hline \multicolumn{3}{c}{ Up to 1999 } & \multicolumn{3}{c}{$\mathbf{1 9 8 0 - 1 9 9 9}$} & \multicolumn{19}{c}{$\mathbf{1 9 8 5 - 1 9 9 9}$} & \multicolumn{2}{c}{$\mathbf{1 9 9 0 - 1 9 9 9}$} \\
\hline 1 & Mas-Colell & 100 & Vives & 100 & Vives & 100 & Galí & 100 \\
2 & Vives & 61.6 & Mas-Colell & 92.5 & Galí & 91.6 & Canova & 84.0 \\
3 & Galí & 51.0 & Galí & 82.7 & Canova & 76.9 & Santos & 82.2 \\
4 & Silvestre & 48.3 & Canova & 69.5 & Santos & 75.4 & Rios-Rull & 61.3 \\
5 & Barberà & 44.1 & Santos & 68.0 & Mas-Colell & 70.1 & Boldrin & 53.9 \\
6 & Canova & 42.8 & Silvestre & 67.4 & Marimon & 56.9 & Saint-Paul & 52.4 \\
7 & Santos & 41.9 & Marimon & 51.3 & Rios-Rull & 56.2 & Vega-Redondo & 52.0 \\
8 & Marimon & 31.6 & Rios-Rull & 50.7 & Vega-Redondo & 55.2 & Vives & 47.6 \\
9 & Rios-Rull & 31.2 & Vega-Redondo & 49.8 & Boldrin & 53.3 & Sala-i-Martin & 45.0 \\
10 & Vega-Redondo & 30.7 & Boldrin & 48.1 & Silvestre & 52.5 & Barberà & 38.4 \\
\hline
\end{tabular}

When considering the time span corresponding to the nineties our results diverge somewhat with Dolado et al. For instance, it is noteworthy that Gilles Saint Paul ranks at the top of our list based on BAU criterion, but does not enter in the original list. This is probably because we have used a different methodology to download the information. 
Some of the shortcomings of the existing databases can explain to certain extent the nature and scope of these differences. However if we compare our results for the total researcher life with the results supplied by Coupé (2005) for the period 1969-2000, there is a high degree of matching, even taking into account we consider slightly different periods .

Table 5 shows the ranking of the ten most cited economists based on citations retrieved in December 2004, adjusted again by the square root of the number of authors. As the reader can see, results change slightly compared with the previous tables. Xavier Sala-iMartin is the best performing researcher, regardless of the period considered. Xavier Vives and Jordi Galí again appear on the top of the lists. Noteworthy Manuel Arellano, who does not appear in any of the tables presented above, is placed between positions $3^{\text {rd }}$ and $5^{\text {th }}$ depending on the time-span considered. Again, Andreu Mas-Colell becomes the most benefited researcher if we consider longer time periods.

Table 5: Classification of researchers according to the adjusted citations received

\begin{tabular}{llrlrlrlr}
\hline & Up to 1999 & & $\mathbf{1 9 8 0 - 1 9 9 9}$ & \multicolumn{3}{c}{$\mathbf{1 9 8 5 - 1 9 9 9}$} & \multicolumn{2}{c}{$\mathbf{1 9 9 0 - 1 9 9 9}$} \\
\hline 1 & Sala-i-Martin & 100 & Sala-i-Martin & 100 & Sala-i-Martin & 100 & Sala-i-Martin & 100 \\
2 & Mas-Colell & 80.9 & Vives & 63.7 & Galí & 47.0 & Galí & 47.0 \\
3 & Vives & 63.7 & Mas-Colell & 58.7 & Vives & 46.0 & Arellano & 45.0 \\
4 & Galí & 47.0 & Galí & 47.0 & Arellano & 45.0 & Dolado & 25.4 \\
5 & Arellano & 45.0 & Arellano & 45.0 & Mas-Colell & 43.0 & Vives & 23.0 \\
6 & Barberà & 31.8 & Dolado & 29.8 & Dolado & 29.8 & Saint-Paul & 22.0 \\
7 & Dolado & 29.8 & Boldrin & 24.8 & Boldrin & 24.8 & Canova & 20.1 \\
8 & Boldrin & 24.8 & Marcet & 23.9 & Marcet & 23.9 & Boldrin & 16.6 \\
9 & Marcet & 23.9 & Barberà & 23.2 & Saint-Paul & 22.0 & Santos & 14.8 \\
10 & Saint-Paul & 22.0 & Saint-Paul & 22.0 & Canova & 20.1 & Motta & 14.5 \\
\hline
\end{tabular}

\section{Extension to 2004}

The results presented up to now here finished in 1999, to fit with Dolado's results. Given that both Econlit and SSCI now supply regular updates of their databases, we are able to present results up to 2004. This extension is interesting since it allows increasing the range of years of publication for the youngest researchers. Therefore we can expect that seniority effect would fade as more junior economists have chances of seeing their work published. As one could expect the range of distances, measured as the distance 
between the first and the tenth best-performing researcher, slightly decreases. This can be easily seen if we compare the last-columns, corresponding to the total researcher life. In contrast, there are no changes in the top positions of the ranking, especially if we consider the longest time-spans: Mas-Colell, Vives and Galí are the three names that repeatedly appear on the top of the lists. The same pattern appears if we extend the ranking based on citations. Again Sala- i-Martin, Galí, and Vives are systematically on the top of the lists.

Table 6: Classification according to the UC3 Criterion

\begin{tabular}{llrlrlllr}
\hline & Up to 2004 & & $\mathbf{1 9 8 0 - 2 0 0 4}$ & & $\mathbf{1 9 8 5 - 2 0 0 4}$ & \multicolumn{2}{c}{$\mathbf{1 9 9 0 - 2 0 0 4}$} \\
\hline 1 & Mas -Colell & 100 & Vives & 100 & Vives & 100 & Galí & 100 \\
2 & Vives & 89.9 & Galí & 76.7 & Galí & 80.6 & Canova & 92.8 \\
3 & Galí & 68.9 & Mas-Colell & 71.3 & Canova & 74.7 & Saint-Paul & 92.3 \\
4 & Canova & 63.9 & Canova & 71.1 & Saint-Paul & 74.4 & Vives & 88.9 \\
5 & Saint-Paul & 63.6 & Saint-Paul & 70.8 & Mas-Colell & 60.2 & Santos & 71.9 \\
6 & Barberà & 54.9 & Santos & 57.0 & Santos & 59.9 & Boldrin & 71.2 \\
7 & Santos & 51.3 & Boldrin & 57.0 & Boldrin & 59.9 & Rios-Rull & 68.6 \\
8 & Boldrin & 51.2 & Rios-Rull & 52.6 & Rios-Rull & 55.3 & Vega-Redondo & 59.4 \\
9 & Rios-Rull & 47.3 & Dolado & 51,3 & Vega-Redondo & 52.2 & Sentana & 58.8 \\
10 & Dolado & 46.2 & Barberà & 51.2 & Dolado & 51.2 & Dolado & 57.2 \\
\hline
\end{tabular}

Table 7: Classification according to the BAU Index

\begin{tabular}{llrlrllllr}
\hline & Up to 2004 & & 1980-2004 & \multicolumn{19}{c}{ 1985-2004 } & \multicolumn{3}{c}{ 1990-2004 } \\
1 & Mas -Colell & 100 & Vives & 100 & Vives & 100 & Saint-Paul & 100 \\
2 & Vives & 85.8 & Saint-Paul & 82 & Saint-Paul & 86.3 & Canova & 83.8 \\
3 & Silvestre & 69.6 & Silvestre & 73.8 & Canova & 72.3 & Vives & 80.8 \\
4 & Saint-Paul & 70.4 & Mas-Colell & 66.3 & Galí & 64.6 & Galí & 74.9 \\
5 & Canova & 58.9 & Canova & 68.7 & Dolado & 63.2 & Dolado & 60.4 \\
6 & Dolado & 54.3 & Dolado & 63.4 & Silvestre & 60.3 & Silvestre & 56.9 \\
7 & Galí & 52.7 & Galí & 61.5 & Mas-Colell & 49.4 & Serrano & 50.5 \\
8 & Barberà & 50.5 & Repullo & 49.8 & Repullo & 48.5 & Santos & 50 \\
9 & Repullo & 42.7 & Vega-Redondo & 45.1 & Vega-Redondo & 48.2 & Sala-i-Martín & 49 \\
10 & Vega-Redondo & 38.6 & Barberà & 42.4 & Santos & 45.2 & Vega-Redondo & 41.9 \\
\hline
\end{tabular}


Table 8: Classificationaccording to the KMS Index

\begin{tabular}{|c|c|c|c|c|c|c|c|c|}
\hline \multicolumn{3}{|c|}{ Up to 2004} & \multirow{2}{*}{$\begin{array}{l}\text { 1980-2004 } \\
\text { Vives }\end{array}$} & \multicolumn{3}{|c|}{ 1985-2004 } & \multicolumn{2}{|c|}{ 1990-2004 } \\
\hline 1 & Mas -Colell & 100.0 & & 100 & Vives & 100 & Santos & 100 \\
\hline 2 & Vives & 67.2 & Mas-Colell & 91.2 & Santos & 88.8 & Galí & 94.7 \\
\hline 3 & Santos & 54.9 & Santos & 81.7 & Galí & 84.1 & Canova & 86.6 \\
\hline 4 & Galí & 52.0 & Galí & 77.4 & Canova & 76.9 & Saint-Paul & 78.3 \\
\hline 5 & Barberà & 49.7 & Canova & 70.7 & Mas-Colell & 73 & Boldrin & 70.0 \\
\hline 6 & Canova & 47.5 & Saint-Paul & 63.9 & Saint-Paul & 69.5 & Rios-Rull & 68.9 \\
\hline 7 & Silvestre & 47.1 & Silvestre & 61 & Boldrin & 65.4 & Sentana & 64 \\
\hline 8 & Saint-Paul & 43.0 & Boldrin & 60.1 & $\begin{array}{l}\text { Vega- } \\
\text { Redondo }\end{array}$ & 61.9 & $\begin{array}{l}\text { Vega- } \\
\text { Redondo }\end{array}$ & 62.9 \\
\hline 9 & Boldrin & 40.4 & $\begin{array}{l}\text { Vega- } \\
\text { Redondo }\end{array}$ & 57 & Rios-Rull & 61.2 & Vives & 61.2 \\
\hline 10 & $\begin{array}{l}\text { Vega- } \\
\text { Redondo }\end{array}$ & 38.3 & Rios-Rull & 56.3 & Sentana & 56.8 & Serrano & 53 \\
\hline
\end{tabular}

Table 9: Classification of researchers according to the adjusted citations received

\begin{tabular}{rlrlrlrlr}
\hline & Up to 2004 & & $\mathbf{1 9 8 0 - 2 0 0 4}$ & \multicolumn{3}{c}{$\mathbf{1 9 8 5 - 2 0 0 4}$} & \multicolumn{3}{c}{$\mathbf{1 9 9 0 - 2 0 0 4}$} \\
1 & Sala-i-Martin & 100 & Sala-i-Martin & 100 & Sala-i-Martín & 100 & Sala-i-Martín & 100 \\
2 & Mas-Colell & 79.4 & Vives & 62.7 & Galí & 53.0 & Galí & 53.0 \\
3 & Vives & 62.7 & Mas-Colell & 58.3 & Vives & 46.0 & Arellano & 39.7 \\
4 & Galí & 53.0 & Galí & 53.0 & Mas-Colell & 43.5 & Boldrín & 25.4 \\
5 & Arellano & 42.9 & Arellano & 42.9 & Arellano & 42.9 & Vives & 24.4 \\
6 & Barberà & 31.4 & Dolado & 28.6 & Dolado & 28.6 & Saint-Paul & 21.9 \\
7 & Dolado & 28.6 & Boldrín & 25.4 & Boldrín & 25.4 & Canova & 19.6 \\
8 & Boldrín & 25.4 & Barberà & 23.3 & Marcet & 23.1 & Santos & 15.8 \\
9 & Marcet & 23.1 & Marcet & 23.1 & Saint-Paul & 21.9 & Dolado & 15.0 \\
10 & Saint-Paul & 21.9 & Saint-Paul & 21.9 & Canova & 19.6 & Barberà & 14.8 \\
\hline
\end{tabular}

Finally, and to complete the analysis we have graphed a scatterplot including the whole sample, plotting the values obtained for a given index against the citations received for the total researcher life. We should expect a positive and strong correlation among both measures: the best performing academics in terms of publications will be precisely those who will be mostly cited. We think however this relationship is not perfectly one-toone: certain articles will deserve special attention for the academic community and will thus obtain an extremely high amount of citations. In that case, the corresponding author will lie significantly above the imaginary $45^{\circ}$ degree line between publications and citations. For the Spanish case only Xavier Sala-i-Martin meets this condition. His paper ("Convergence", (1992)) has received 458 citations (229 if we adjust for the number of authors) up to December 2004. 


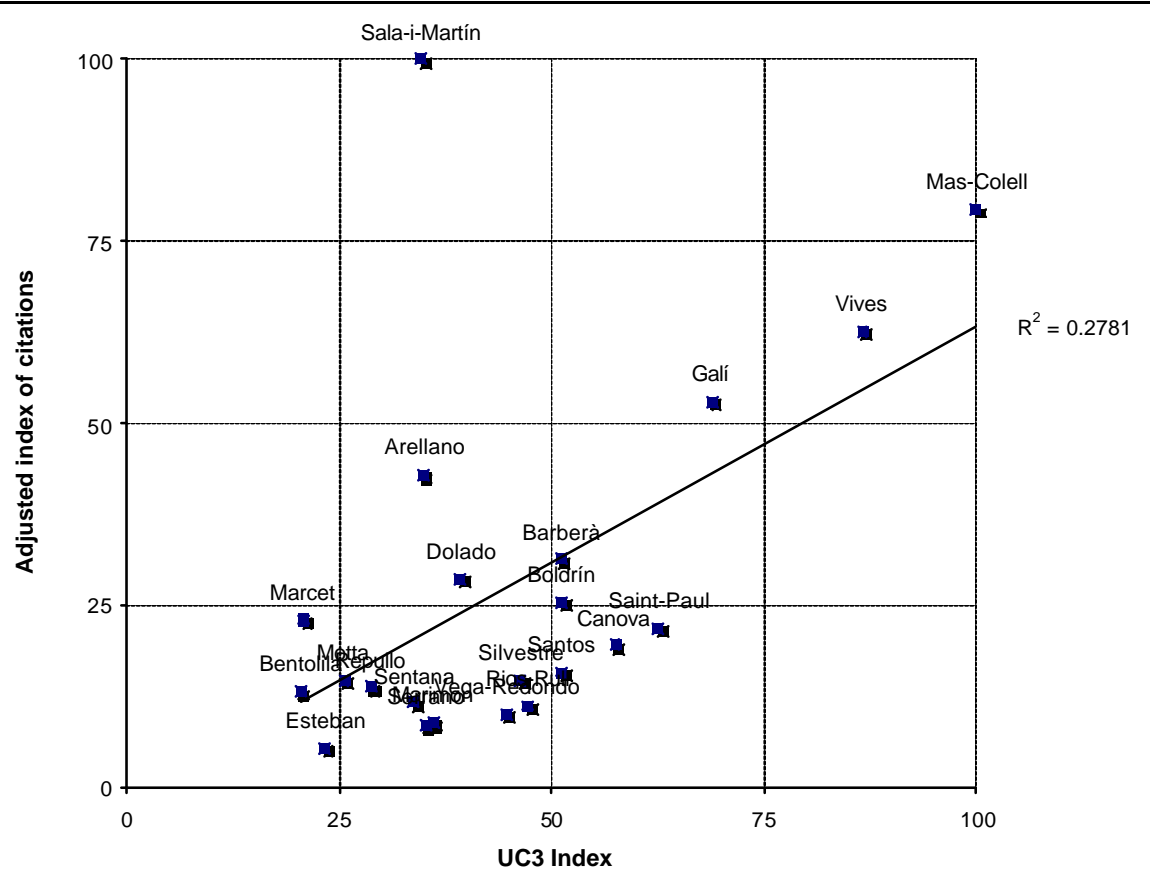

Picture 1: Publication-measures (UC3 index) agai nst citations received (total researcher life)

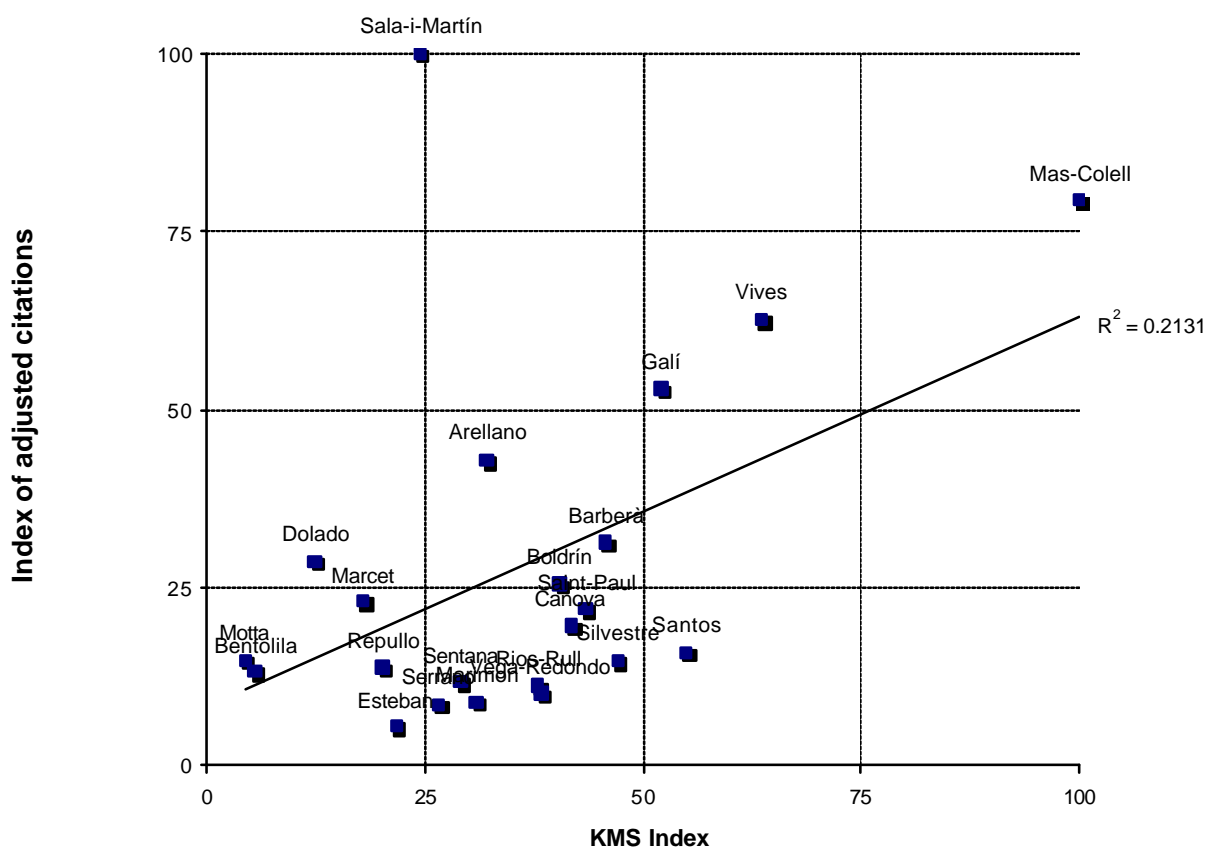

Picture 2: Publication-measures (KMS index) against citations received (total researcher life) 


\section{References}

Adam, David (2002). "The counting house", Nature, 415, 726-729.

Bauwens, Luc (1998) "A new method to rank University Research and Researchers in Economics in Belgium", mimeo, CORE, Université Catholique de Louvain, Belgium. Available at http://www.core.ucl.ac.beleconometrics/bauwens/rankings/Method.doc (Last accessed: February 7th, 2005).

Coupé, Tom (2003), "Revealed Performances : Worldwide Rankings of Economists and Economics Departments, 1990-2000', Journal of the European Economic Association, 1(6), 1309-1345.

Coupé, Tom (2005) 'Nobel' list: publications 1969-2000". Available at http://student.ulb.ac.be/ tcoupe/update/nobelpub.html (Last accessed: February 17th, 2005).

Dolado J.J., García-Romero, A and G. Zamarro (2003). "Publishing Performance in Economics: Spanish Rankings (1990-1999)", Spanish Economic Review, 5, 80-103.

Kalaitzidakis, P., Mamuneas, M. and T. Stengos (2003). "Rankings of Academic Journals and Institutions in Economics", Journal of the European Economic Association, 1(6), 1346-1366.

Laband, David N. and Michael J. Piette (1994). "The Relative Impacts of Economics Journals" (1970-1990). Journal of Economic Literature, 32(2), 640-666. 